\title{
The Role of Primary Care Experiences in Obtaining Treatment for Depression
}

\author{
Audrey L. Jones, Ph.D. ${ }^{1,2}$, Maria K. Mor, Ph.D., ${ }^{3,4}$, Gretchen L. Haas, Ph.D., 5, \\ Adam J. Gordon, M.D., M.P. H. $^{1,2}$, John P. Cashy, Ph.D. ${ }^{3}$, James H. Schaefer Jr, M.P.H', and \\ Leslie R. M. Hausmann, Ph.D. 3.8
}

\begin{abstract}
'Informatics, Decision-Enhancement and Analytic Sciences Center of Innovation (IDEAS 2.0), Veterans Affairs Salt Lake City Health Care System, Salt Lake City, UT, USA; ${ }^{2}$ Department of Internal Medicine, University of Utah School of Medicine, Salt Lake City, UT, USA; ${ }^{3}$ Center for Health Equity Research and Promotion (CHERP), VA Pittsburgh Healthcare System, Pittsburgh, PA, USA; ${ }^{4}$ Department of Biostatistics, University of Pittsburgh Graduate School of Public Health, Pittsburgh, PA, USA; ${ }^{5}$ Department of Psychiatry, University of Pittsburgh School of Medicine, Pittsburgh, PA, USA; ${ }^{6}$ VISN4 Mental IIIness Research, Education, and Clinical Center, Veterans Affairs Pittsburgh Healthcare System, Pittsburgh, PA, USA; ${ }^{7}$ Department of Veterans Affairs Office of Reporting, Analytics, Performance, Improvement and Deployment, Durham, NC, USA; ${ }^{8}$ Division of General Internal Medicine, Department of Medicine, University of Pittsburgh School of Medicine, Pittsburgh, PA, USA.
\end{abstract}

BACKGROUND: Managing depression in primary care settings has increased with the rise of integrated models of care, such as patient-centered medical homes (PCMHs). The relationship between patient experience in PCMH settings and receipt of depression treatment is unknown.

OBJECTIVE: In a large sample of Veterans diagnosed with depression, we examined whether positive PCMH experiences predicted subsequent initiation or continuation of treatment for depression.

DESIGN AND PARTICIPANTS: We conducted a lagged cross-sectional study of depression treatment among Veterans with depression diagnoses $(n=27,362)$ in the years before (Y1) and after (Y2) they completed the Veterans Health Administration's national 2013 PCMH Survey of Healthcare Experiences of Patients.

MAIN MEASURES: We assessed patient experiences in four domains, each categorized as positive/moderate/ negative. Depression treatment, determined from administrative records, was defined annually as 90 days of antidepressant medications or six psychotherapy visits. Multivariable logistic regressions measured associations between $\mathrm{PCMH}$ experiences and receipt of depression treatment in Y2, accounting for treatment in Y1.

KEY RESULTS: Among those who did not receive depression treatment in Y1 $(n=4613)$, positive experiences in three domains (comprehensiveness, shared decisionmaking, self-management support) predicted greater initiation of treatment in Y2. Among those who received depression treatment in Y1 $(n=22,749)$, positive or moderate experiences in four domains (comprehensiveness, care coordination, medication decision-making, self-management support) predicted greater continuation of treatment in Y2. CONCLUSIONS: In a national PCMH setting, patient experiences with integrated care, including care coordination,

Electronic supplementary material The online version of this article (https://doi.org/10.1007/s11606-018-4522-7) contains supplementary material, which is available to authorized users.

Received November 3, 2017

Revised April 3, 2018

Accepted May 24, 2018

Published online June 8, 2018 comprehensiveness, involvement in shared decision-making, and self-management support predicted patients' subsequent initiation and continuation of depression treatment over time-a relationship that could affect physical and mental health outcomes.

KEY WORDS: patient-centered care; depression; primary care; veterans.

J Gen Intern Med 33(8):1366-73

DOI: $10.1007 / \mathrm{s} 11606-018-4522-7$

(C) Society of General Internal Medicine (This is a U.S. Government work and not under copyright protection in the US; foreign copyright protection may apply) 2018

$\mathrm{O}$ ne in six adults experiences a major depressive disorder during their lifetime. ${ }^{1}$ Despite availability of effective antidepressant and psychotherapy treatments, less than half of patients with depressive disorders (henceforth "depression") receive treatment, ${ }^{2,3}$ potentially contributing to poor clinical outcomes and premature mortality. ${ }^{4,5}$ A number of barriers to depression treatment have been identified, including lack of insurance, rural residence, low perceived need, stigmatizing attitudes towards mental health treatment, and fragmentation of care. ${ }^{6-9}$ Another factor that may contribute to suboptimal treatment of depression is patient dissatisfaction with experiences in the primary care environment, which can lead to avoidance or premature termination of depression treatment. ${ }^{10,11}$

The majority (57\%) of patients treated for depression receive some of their depression care in primary care, ${ }^{12}$ and these trends are increasing with primary care integration. ${ }^{13}$ Prior studies, conducted with general outpatient populations, have found that positive primary care experiences are associated with patients' receipt of recommended preventive screenings and adherence to physicians' advice. ${ }^{14-20}$ It is possible that patient experiences with care in this setting are also a factor in depression treatment. ${ }^{21-23}$ Indeed, one study found that positive ratings of provider communication predicted antidepressant prescription refills and number of antidepressant days 
treated over 12 months. ${ }^{21}$ Another study found patient perceptions of involvement in decision-making were associated with increased receipt of guideline-concordant treatment and greater depression remission. ${ }^{22}$

The few studies of primary care experiences that have focused on experiences of depressed persons were limited by small samples, did not account for prior treatment, or focused on a single care domain, such as provider communication or patient involvement in decision-making. ${ }^{21,23-26}$ Within integrated care models, such as patient-centered medical homes (PCMHs), experience domains of comprehensiveness (attending to mental and physical health concerns in primary care), coordination of services, and chronic care management could also affect patients' access to and utilization of depression treatment. For example, provider attention to mental health concerns could prompt patients to disclose symptoms, while positive experiences with care coordination could indicate potential for referrals to mental health specialists, and self-management support could be a factor in patients' self-care behaviors and maintenance in treatment over time. To our knowledge, primary care experiences with comprehensiveness, care coordination, and selfmanagement support in a PCMH setting have not been examined for their relationship to depression treatment.

We attempted to address these gaps by examining receipt of depression treatment in the 12 months prior to an assessment of experiences in primary care (i.e., year 1) and in the 12 months following that experience (i.e., year 2) in the Veterans Health Administration (VHA). The VHA is an optimal setting to consider whether PCMH domains are a factor in depression treatment because VHA has implemented a PCMH model of care nationally (called Patient Aligned Care Teams), ${ }^{27,28}$ and has undertaken initiatives to integrate mental health treatment within this setting. ${ }^{29-31} \mathrm{We}$ assessed patient experience in four PCMH domains: comprehensiveness, care coordination, selfmanagement support, and involvement in shared decisionmaking. We hypothesized that, regardless of prior depression treatment, patients with positive PCMH experiences would be more likely to initiate and continue treatment in year 2 .

\section{METHODS}

\section{Design}

We conducted a lagged cross-sectional study of primary care experiences and depression treatment in a national sample of patients receiving primary care services in VHA medical centers and outpatient facilities in fiscal year 2013. Study procedures were approved by the institutional review boards at the University of Utah and VA Pittsburgh Healthcare System.

\section{Data Sources and Study Sample}

We linked data from VHA's 2013 Patient-Centered Medical Home Survey of Healthcare Experiences of Patients (PCMHSHEP) with administrative data from the VHA Corporate Data
Warehouse. The PCMH-SHEP is an ongoing survey of primary care experiences conducted by the VHA Office of Reporting, Analytics, Performance, Improvement and Deployment. ${ }^{32}$ Veterans age 18 or older are eligible for the PCMH-SHEP if they received VHA outpatient services in an index month, had a primary care visit with an assigned provider in the 10 months prior to the index month, and did not participate in the prior year's survey. Each month, a stratified, random sample of eligible Veterans is mailed a letter explaining the goals of the survey, then mailed a survey the subsequent week, and sent a final thank you/reminder postcard the third week. Approximately $45 \%$ of eligible Veterans respond to the PCMH-SHEP each month.

For this study, we included PCMH-SHEP respondents with ICD-9 diagnoses of major depressive disorder or depressive disorder, not otherwise specified in their VHA medical record. Specifically, respondents were eligible if they had one inpatient visit or two outpatient visit days with a diagnosis recorded within the year prior to their PCMH-SHEP survey (year 1). The criteria of one inpatient or two outpatient diagnoses were selected based on its superior performance in prior research aimed at identifying patients with mental health disorders from VHA administrative data (depression positive predictive value $=0.88$, depression negative predictive value $=0.71) .{ }^{33}$ To isolate the cohort to patients with continued need for depression treatment in year 2, we excluded persons with diagnoses of depression in remission in year 1 and those without an active depression diagnosis in year 2 . We also excluded respondents with comorbid bipolar or psychotic disorder, as these persons could be treated according to VHA bipolar disorder and schizophrenia treatment guidelines. Additionally, we excluded respondents with missing data on one or more sociodemographic variables of interest (described below) (Fig. 1).

\section{Primary Care Experiences}

Patient-reported experiences with care were assessed in the 2013 PCMH-SHEP survey, which is based on the Consumer Assessment of Health Plans and Systems (CAHPS) survey. ${ }^{34,35}$ The PCMH-SHEP asks patients if they received care from an assigned primary care provider and, if yes, to report on experiences with that provider in the past 12 months. We grouped items into the domains of comprehensiveness, coordination, medication decision-making, and self-management support based on the CAHPS PCMH Supplement 2.0..$^{34,35}$ The comprehensiveness domain assesses whether providers pay attention to mental or emotional health. Care coordination assesses whether providers are informed about care from specialists. Medication shared decision-making assesses whether providers discussed medication decisions with patients, while self-management assesses whether providers support patients in taking care of their own health.

For domains with two or more items, we calculated composite scores as the average of non-missing items for each individual, then categorized the composite scores as negative, 


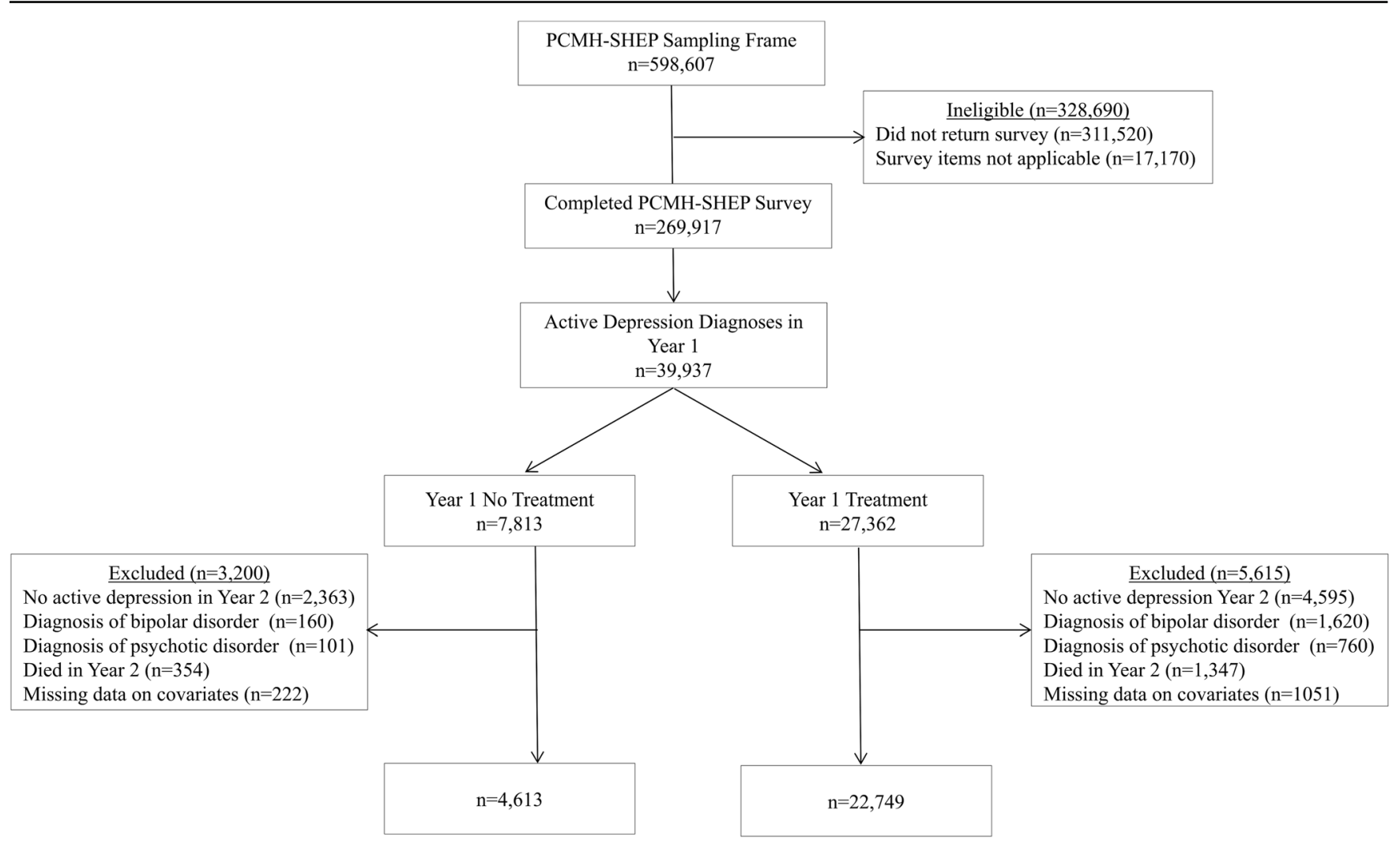

Figure 1 Inclusion and exclusion criteria applied to create an analytic sample of Veterans who completed the 2013 Veterans Healthcare Administration Patient Centered Medical Home Survey of Healthcare Experiences of Patients (PCMH-SHEP) and had an active diagnosis of depression in the year prior to and following the PCMH-SHEP. Exclusion criteria were applied sequentially.

moderate, or positive using previously published cutoffs. ${ }^{36} \mathrm{~A}$ list of the specific domain items, response options, and composite cutoffs is available in Table 1.

\section{Depression Treatment}

We extracted psychotherapy procedure codes and antidepressant pharmacy records from VHA administrative data in the 12 months prior to when each patient completed the 2013 PCMH-SHEP (year 1) and the 12 months following survey completion (year 2). Because most patients with depression diagnoses received some treatment, we sought to identify patients receiving a minimal threshold of depression care consistent with evidence-based VHA practice guidelines. ${ }^{37}$ When data used in this study were collected, practice guidelines included antidepressant medication (response often occurs within the first 6 to 12 weeks of therapy), and evidencebased psychotherapies (e.g., 6 sessions of problem-solving therapy typically delivered in primary care, 16-20 sessions of cognitive-behavioral therapy or interpersonal psychotherapy typically delivered in specialty mental health clinics).

In each year (years 1 and 2), we categorized depression treatment as "yes" if the patient received antidepressant prescription covering 90 days (i.e., $>12$ weeks), or if patients received at least six visits to any healthcare setting with a psychotherapy procedure code; treatment was categorized as "no" if patients did not receive a minimal threshold of treatment within that year (including no treatment). This definition reflects a minimal threshold of services based on VHA practice guidelines (see Hahm et al. ${ }^{38}$ for similar approaches) and may not approximate depression quality metrics. ${ }^{39}$

\section{Covariates}

We controlled for variables known to be associated with patient experiences with care and access to depression treatment. ${ }^{40-43}$ Age, sex, and marital status were drawn from the administrative record closest to the PCMH-SHEP survey date. Self-reported race/ethnicity, education, and perceived mental health (i.e., "would you rate your mental or emotional health: excellent, very good, good, fair, poor?") were drawn from the PCMH-SHEP. Co-occurring mental health and substance use disorder diagnoses, Charlson Comorbidity Index scores, and US urban versus rural geography were determined from administrative records in year $1.33,44$

To account for exposures to primary care and mental health specialists, we controlled for number of visits to each type of clinic in year 1 . We also controlled for number of visits in clinics with primary care-mental health integration (PC-MHI), defined by the co-location of mental health providers in primary care and/or receipt of mental health case management. ${ }^{45}$

\section{Statistical Analyses}

Analyses were conducted using Stata 13.0. ${ }^{46}$ We applied PCMH-SHEP survey weights to account for participant 
Table 1 Description of Patient Experience Domains, Response Options, Reliability, and Domain Score Ranges Comprising Negative, Moderate, and Positive Experiences

\begin{tabular}{|c|c|c|c|c|c|}
\hline \multirow[b]{2}{*}{ Domain: survey items } & \multirow[b]{2}{*}{ Response options } & \multirow[b]{2}{*}{ Reliability } & \multicolumn{3}{|c|}{ Domain score ranges } \\
\hline & & & Negative & Moderate & Positive \\
\hline $\begin{array}{l}\text { Comprehensiveness: In the last } 12 \text { months, did anyone in } \\
\text { this provider's office ... } \\
\text {...ask you if there was a period of time when you felt sad, } \\
\text { empty, or depressed? } \\
\text {...talk about things in your life that worry you or cause } \\
\text { you stress? } \\
\text {...talk about a personal problem, family problem, alcohol } \\
\text { use, drug use, or a mental or emotional illness? }\end{array}$ & No, yes $(0,1)$ & 0.81 & 0 & $0.01-0.99$ & 1.0 \\
\hline $\begin{array}{l}\text { Care coordination: In the last } 12 \text { months, how often did } \\
\text { [provider] seem informed and up-to-date about the care you } \\
\text { got from specialists? }\end{array}$ & $\begin{array}{l}\text { Never, sometimes usually, } \\
\text { always }(1-4)\end{array}$ & NA & 1 & $2-3$ & 4 \\
\hline $\begin{array}{l}\text { Medication decision-making: When you talked about starting } \\
\text { or stopping a prescription medicine ... } \\
\text {...how much did this provider talk about the reasons you } \\
\text { might want to take the medicine? } \\
\text {...how much did this provider talk about the reasons you } \\
\text { might not want to take a medicine? } \\
\text {...did this provider ask you what you thought was best for you? }\end{array}$ & $\begin{array}{l}\text { Never, sometimes usually, } \\
\text { always }(1-4) \\
\text { No, yes }(1,4)\end{array}$ & 0.74 & $1.00-2.00$ & $2.01-3.67$ & $3.68-4.00$ \\
\hline $\begin{array}{l}\text { Self-management support: In the last } 12 \text { months, did anyone } \\
\text { in this provider's office ... } \\
\text {...talk with you about specific goals for your health? } \\
\text {...ask you if there are things that make it hard for you to take } \\
\text { care of your health? }\end{array}$ & No, yes $(0,1)$ & 0.68 & 0 & $0.01-0.99$ & 1.00 \\
\hline
\end{tabular}

Domains were drawn from the Veterans Health Administration (VHA)'s 2013 Patient-Centered Medical Home Survey of Healthcare Experiences of Patients. For multi-item domains, reliability was calculated as the correlation of items within the domain, and domain scores as the average of nonmissing items. The domain scores were categorized as negative, moderate, or positive, with the negative and positive score ranges determined separately for each domain. Participants included 27,362 VHA outpatients with active depression diagnoses in the 12 months prior to and following the survey

N/A reliability not applicable as the domain includes only one item

selection and survey non-response. Standard errors were estimated using a Taylor series approximation that accounted for the stratified sampling design. We used survey design-adjusted Rao-Scott chi-square tests to compare the sociodemographic and clinical characteristics of patients receiving versus not receiving depression treatment in year 1 .

We used multivariable logistic regression methods to measure the association between year 1 primary care experiences and year 2 receipt of depression treatment. Because we expected that patients' receipt of depression treatment in year 2 might depend on their prior treatment, we stratified our analyses by year 1 receipt of depression treatment (yes or no). Models were run separately for each patient experience domain, and coefficients were converted to risk differences to aid interpretation.

We conducted sensitivity analyses to determine if study estimates differ with alternative treatment definitions and evidence of patient discussions with their primary care provider in year 1. First, we reran study models for a subsample of patients with no antidepressant or psychotherapy in year 1 . Second, because patients with a PC-MHI visit were likely to have discussed mental health with their provider, we reran study models for these patients, specifically.

\section{RESULTS}

Of the 598,607 VHA outpatients included in the 2013 PCMHSHEP sampling frame, 269,917 (45\%) completed the survey.
Responders were less likely than non-responders to have past year depression diagnoses (15 vs $22 \%$, respectively), were older (means $=62$ vs 54 years), were more likely to be male (91 vs $85 \%$ ) and married (57 vs $47 \%$ ), and were less likely to have substance use disorder diagnoses (13 vs 18\%). Among Veterans in the sampling frame with depression diagnoses, responders were more likely to receive depression treatment in year 1 ( $80 \mathrm{vs} 37 \%$ ).

Of the 39,937 completers with active depression diagnoses in year $1,17 \%$ received no treatment in year 1 , whereas $83 \%$ received pharmacotherapy, psychotherapy, or both. After excluding participants without active depression in year 2, with bipolar or psychotic disorder diagnoses, and those with missing data on covariates of interest, the final sample included 4613 untreated and 22,749 treated Veterans.

\section{Sociodemographic and Clinical Characteristics of Patients Based on Receipt of Treatment for Depression in Year 1}

Compared to those not treated in year 1, patients who received depression treatment were more likely to be older, nonHispanic white, married, and insured by Medicare or Medicaid (Table 2). In addition, those who received depression treatment in year 1 were more likely to have a Charlson comorbidity score $\geq 2$, to rate their mental health as "fair" or "poor," and to have diagnoses of post-traumatic stress disorder, other anxiety disorders, and alcohol or drug abuse or dependence. 
Table 2 Sociodemographic and Clinical Characteristics of Patients Based on Receipt of Depression Treatment in Year $1(n=27,362)$

\begin{tabular}{|c|c|c|c|}
\hline & \multicolumn{2}{|c|}{ Depression treatment in year 1} & \multirow[b]{4}{*}{$p$ value* } \\
\hline & No & Yes & \\
\hline & $n=4613$ & $n=22,749$ & \\
\hline & Weighted \% & Weighted \% & \\
\hline Female sex & 15.0 & 13.2 & 0.08 \\
\hline Age & & & $<0.001$ \\
\hline Age $18-44$ & 27.8 & 20.6 & \\
\hline Age $45-54$ & 18.0 & 19.4 & \\
\hline Age $55-64$ & 28.8 & 33.3 & \\
\hline Age $65-74$ & 18.1 & 21.3 & \\
\hline Age $75+$ & 7.3 & 5.3 & \\
\hline Race/ethnicity & & & 0.01 \\
\hline Non-Hispanic White & 61.1 & 65.34 & \\
\hline Non-Hispanic Black & 21.9 & 18.92 & \\
\hline Hispanic & 11.5 & 10.29 & \\
\hline Other & 5.5 & 5.45 & \\
\hline Marital status & & & $<0.001$ \\
\hline Married & 48.6 & 54.0 & \\
\hline Previously married & 34.9 & 33.1 & \\
\hline Never married & 16.7 & 12.9 & \\
\hline Education & & & 0.26 \\
\hline$<12$-year education & 6.1 & 5.9 & \\
\hline High school equivalent & 29.8 & 28.1 & \\
\hline Some college & 45.5 & 45.9 & \\
\hline 4 -year college degree & 18.6 & 20.1 & \\
\hline Rural US residence & 32.7 & 34.4 & 0.12 \\
\hline Type(s) of insurance ${ }^{\dagger}$ & J2.1 & & \\
\hline Private & 34.4 & 32.5 & 0.12 \\
\hline Medicaid/medicare & 37.5 & 45.5 & $<0.001$ \\
\hline Charlson comorbidity & & & $<0.001$ \\
\hline 0 & 53.7 & 46.9 & \\
\hline 1 & 22.3 & 26.0 & \\
\hline$\geq 2$ & 24.0 & 27.1 & \\
\hline $\bar{M}$ ental health rated fair/poor & 61.1 & 69.1 & $<0.001$ \\
\hline Psychiatric diagnoses ${ }^{\dagger}$ & & & \\
\hline Post-traumatic stress disorder & 21.7 & 43.8 & $<0.001$ \\
\hline Other anxiety disorders & 19.1 & 26.3 & $<0.001$ \\
\hline Alcohol use disorder & 8.8 & 11.6 & $<0.001$ \\
\hline Drug use disorder & 5.3 & 7.9 & $<0.001$ \\
\hline Number of primary care clinic visits (mean) & 5.9 & 7.5 & $<0.001$ \\
\hline Number of mental health clinic visits (mean) & 4.4 & 16.8 & $<0.001$ \\
\hline Number of PC-MHI visits (mean) & 0.7 & 0.9 & 0.05 \\
\hline
\end{tabular}

*p value obtained from chi-square test of differences for categorical outcomes, and ANOVA for continuous outcomes

†Categories were not mutually exclusive. Therefore, columns do not add to $100 \%$

PC-MHI primary care-mental health integration

Those who received depression treatment in year 1 had more primary care and mental health clinic visits than those not receiving treatment in year 1 .

\section{Association of Positive, Moderate, and Negative Experiences with Primary Care from Year 1 with Subsequent Initiation of Treatment for Depression in Year 2}

Of the 4613 patients not treated in year 1, 46\% initiated depression treatment in year 2. After controlling for sociodemographic and clinical characteristics, patients reporting positive primary care experiences in year 1 were more likely than those reporting moderate and/or negative experiences to initiate treatment in year 2 (Table 3 ). This pattern was observed for comprehensiveness (positive vs moderate $\mathrm{RD}=12.6$, positive vs negative $\mathrm{RD}=9.7$ ), shared decision-making (positive vs negative $\mathrm{RD}=10.5$ ), and self- management support (positive vs moderate $\mathrm{RD}=5.9$, positive vs negative $\mathrm{RD}=7.4$ ).

\section{Association of Positive, Moderate, and Negative Experiences with Primary Care from Year 1 with Subsequent Continuation of Treatment for Depression in Year 2}

Of the 23,081 patients who received depression treatment in year $1,89 \%$ continued to receive treatment in year 2 . Patients with positive and/or moderate primary care experiences were more likely than those with negative experiences to continue depression treatment in year 2 (Table 4). This pattern was observed for comprehensiveness ( $\mathrm{RDs}=2.4$ and 1.9) and selfmanagement support (RDs $=3.2$ and 2.2). Moreover, patients with positive versus negative experiences with care coordination and medication decision-making were more likely to continue depression treatment ( $\mathrm{RDs}=3.6$ and 3.8, respectively). 
Table 3 Association of Positive, Moderate, and Negative Experiences with Primary Care from Year 1 with Subsequent Initiation of Depression Treatment in Year $2(n=4613)$

\begin{tabular}{|c|c|c|c|c|c|c|}
\hline \multirow[b]{2}{*}{ Patient experience domain } & \multicolumn{3}{|c|}{$\begin{array}{l}\text { Probability of initiating depression } \\
\text { treatment in year } 2 \text {, by healthcare } \\
\text { experience }\end{array}$} & \multicolumn{3}{|c|}{ Adjusted risk differences } \\
\hline & Positive & Moderate & Negative & Positive vs moderate & Moderate vs negative & Positive vs negative \\
\hline Comprehensiveness & 50.4 & 37.9 & 40.7 & $12.6^{\ddagger}$ & -2.8 & $9.7^{\dagger}$ \\
\hline Care coordination & 46.7 & 44.5 & 52.3 & 2.2 & -7.8 & -5.6 \\
\hline Medication decision-making & 50.9 & 47.9 & 40.4 & 3.0 & 7.6 & $10.5^{*}$ \\
\hline
\end{tabular}

\section{Sensitivity Analyses}

Among 1293 Veterans who did not receive any antidepressant or psychotherapy of any duration in year 1 , the treatment initiation $\mathrm{RD}$ estimates for positive versus negative experiences were of a similar or greater magnitude than the original study estimates in Table 3 . The RD estimates associated with positive versus negative experiences with comprehensiveness and self-management support were statistically significant (Online Appendix 1).

Among 1027 Veterans who had a PC-MHI visit and therefore were likely to have discussed mental health with their provider, the treatment initiation RD estimates for positive versus negative experiences were of a similar magnitude to the main study estimates, but no longer reached the threshold for statistical significance (Online Appendix 2).

\section{DISCUSSION}

In a large sample of VHA outpatients diagnosed with depression, we sought to determine relationships between primary care experiences and subsequent participation in depression treatment. We found, regardless of prior treatment history, that patients with positive primary care experiences in key domains were more likely to receive depression treatment in the year following an assessment of primary care experiences. For those not treated in year 1, positive (vs moderate or negative) experiences with comprehensiveness, shared decision-making and self-management support predicted greater initiation of depression treatment in year 2. For those who had received depression treatment in year 1, patients with positive or moderate (vs negative) experiences with comprehensiveness, care coordination, medication decision-making, and selfmanagement support were more likely to continue treatment in year 2.

While prior studies have examined patient-provider relationship factors (such as communication and shared decisionmaking) in antidepressant adherence, ${ }^{47-49}$ this study examines patient experiences with aspects of integrated care (e.g., comprehensiveness, care coordination, self-management support) that have not been previously assessed for their relationship with depression treatment. Our finding that positive experiences with comprehensiveness (defined as provider attention to mental health issues) and self-management support (defined as attention to health goals) from year 1 predicted subsequent initiation of depression treatment offers hope that a wholeperson orientation in PCMH settings could facilitate depression treatment. The risk difference estimates associated with treatment initiation ranged from 7.4 to 12.6 percentage points, reflecting a sizeable (17-26\%) increase in the probability of depression treatment.

One concern that we took into account in our study design was that negative primary care experiences might discourage patients from continuing depression treatment. To address this concern, we examined relationships of primary care experiences with subsequent depression treatment in the subsample of patients already receiving treatment in year 1 . We found no differences in treatment continuation for those with positive

Table 4 Association of Positive, Moderate, and Negative Experiences with Primary Care from Year 1 with Subsequent Continuation of Depression Treatment in Year $2(n=22,749)$

\begin{tabular}{|c|c|c|c|c|c|c|}
\hline \multirow[b]{2}{*}{ Patient experience domain } & \multicolumn{3}{|c|}{$\begin{array}{l}\text { Probability of continuing } \\
\text { depression treatment in year } 2 \text {, by } \\
\text { healthcare experience }\end{array}$} & \multicolumn{3}{|c|}{ Adjusted risk differences } \\
\hline & Positive & Moderate & Negative & Positive vs moderate & Moderate vs negative & Positive vs negative \\
\hline Comprehensiveness & 89.4 & 89.9 & 87.5 & -0.5 & $2.4 *$ & $1.9 *$ \\
\hline Care coordination & 90.2 & 89.3 & 86.6 & 0.8 & 2.7 & $3.6^{*}$ \\
\hline Medication decision-making & 90.4 & 89.1 & 86.6 & 1.3 & 2.5 & $3.8^{\dagger}$ \\
\hline Self-management support & 89.6 & 90.6 & 87.4 & -1.0 & $3.2^{\ddagger}$ & $2.2^{\dagger}$ \\
\hline
\end{tabular}


versus moderate experiences in any domain, but reduced continuation for those with negative versus positive and/or negative versus moderate experiences in all four domains. The pattern of results suggests that the negative experiences with primary care sometimes reported by depressed patients ${ }^{50}$ might contribute to premature termination of treatment. While the estimated differences in treatment continuation for those with negative versus moderate or positive experiences were small ( $2-4$ percentage points), these differences reflect a linkage between patient experiences and treatment continuation that is worthy of further study as it could adversely impact clinical outcomes.

Most $(80 \%)$ survey respondents in this study of VHA outpatients with depression received treatment, a rate that is much higher than what has been observed in non-clinical samples ${ }^{2,3}$ and among Medicaid enrollees. ${ }^{8}$ VHA is unique from other healthcare settings in that insurance and cost barriers to care are largely reduced, and VHA has implemented many initiatives to screen for, assess, and treat depressive disorders in primary care. ${ }^{29-31}$ While VHA appears to exceed other healthcare systems in providing depression treatment, ${ }^{39}$ our observation that $20 \%$ of depressed survey respondents were not treatment engaged suggests that opportunities for improvement remain. Moreover, our finding of suboptimal depression treatment among survey non-respondents (37\%) suggests that this is a vulnerable group who might benefit from additional follow-up.

We note study limitations. First, our sample included VHA outpatients with depression diagnoses, which are often assigned at the time of treatment. Our findings do not generalize to undiagnosed or misdiagnosed VHA patients, or to depressed persons who did not receive care in the VHA system. Because our sample included Veterans more likely to be engaged in depression treatment, estimates of associations between positive PCMH experiences and subsequent depression treatment initiation are optimistic. It will be important for future studies to test whether positive primary care experience relate to depression treatment in reluctant patients. Second, because depression screens were not routinely administered to patients in treatment, we had limited information on clinical severity. Third, our measure of pharmacotherapy is based on administrative records of pharmacy fills and does not indicate whether patients took antidepressants as prescribed. ${ }^{51}$ Finally, the observational nature of the study design prevented us from determining causal associations between primary care experiences and subsequent participation in depression treatment. There could be unmeasured factors, such as patient activation, that relate to positive healthcare experiences ${ }^{52}$ and depression treatment. Our study findings are more suggestive than definitive, and set the stage for prospective studies in integrated primary care settings.

Despite limitations, our results suggest that $\mathrm{PCMH}$ domains of primary care including comprehensiveness, involvement in shared decision-making, and self-management support are important predictors of patients' initiation of depression treatment over time - a relationship which could affect physical and mental health outcomes. As healthcare practices and systems track patient satisfaction and measures of healthcare experiences, research is needed to test whether interventions to improve primary care experiences impact depression treatment initiation or continuation.

Acknowledgments: Dr. Jones is supported as a VA Office of Academic Affiliations Associated Health Professions Post-Doctoral Fellow in Medical Informatics (TMI 95-660) at the Informatics, Decision-Enhancement and Analytic Sciences Center (\#150HX001240) at the VA Salt Lake City Health Care System.

Results from this study were presented as a poster at the 2016 American Public Health Association Annual Meeting in Denver, CO, and the 2017 VA Health Services Research and Development and Quality Enhancement Research Initiative National Meeting in Crystal Springs, VA.

Corresponding Author: Audrey L. Jones, Ph.D.; Informatics, Decision-Enhancement and Analytic Sciences Center of Innovation (IDEAS 2.0)Veterans Affairs Salt Lake City Health Care System, Salt Lake City, UT, USA (e-mail: Audrey.Jones3@va.gov).

Funding Information The work reported here was supported by the Department of Veterans Affairs VISN4 CHERP Competitive Research Pilot Program (LIP 72-081).

\section{Compliance with Ethical Standards:}

Conflict of Interest: The authors declare that they do not have a conflict of interest.

Disclaimer: The contents of this article do not represent the views of the Department of Veterans Affairs or the United States Government.

\section{REFERENCES}

1. Kessler RC, Berglund P, Demler O, et al. The epidemiology of major depressive disorder: results from the National Comorbidity Survey Replication (NCS-R). J Am Board Fam Med. 2003;289(23):3095-3105.

2. Gonzalez HM, Vega WA, Williams DR, Tarraf W, West BT, Neighbors HW. Depression care in the United States: too little for too few. Arch Gen Psychiatry. 2010;67(1):37-46.

3. Young AS, Klap R, Sherbourne CD, Wells KB. The quality of care for depressive and anxiety disorders in the United States. Arch Gen Psychiatry. 2001;58(1):55-61.

4. Hepner KA, Rowe M, Rost $\mathbf{K}$, et al. The effect of adherence to practice guidelines on depression outcomes. Ann Intern Med. 2007;147(5):320-329.

5. Watkins KE, Paddock SM, Hudson TJ, et al. Association between quality measures and mortality in individuals with co-occurring mental health and substance use disorders. J Subst Abuse Treat. 2016;69:1-8.

6. Campbell DG, Bonner LM, Bolkan CR, et al. Stigma predicts treatment preferences and care engagement among Veterans Affairs primary care patients with depression. Ann Behav Med. 2016;50(4):533-544.

7. Fortney JC, Harman JS, Xu S, Dong F. The association between rural residence and the use, type, and quality of depression care. $J$ Rural Health. 2010;26(3):205-213.

8. Teh CF, Sorbero MJ, Mihalyo MJ, et al. Predictors of adequate depression treatment among medicaid-enrolled adults. Health Serv Res. 2010;45(1):302-315.

9. Duhoux A, Fournier L, Gauvin L, Roberge P. Quality of care for major depression and its determinants: a multilevel analysis. BMC Psychiatry. 2012;12:142.

10. True G, Rigg KK, Butler A. Understanding barriers to mental health care for recent war veterans through photovoice. Qual Health Res. 2015;25(10): 1443-1455.

11. Spoont M, Nelson D, van Ryn M, Alegria M. Racial and ethnic variation in perceptions of VA mental health providers are associated with treatment retention among veterans with PTSD. Med Care. 2017;55(Suppl 9 Suppl 2):S33-S42. 
12. Wang PS, Lane M, Olfson M, Pincus HA, Wells KB, Kessler RC. Twelvemonth use of mental health services in the United States: results from the National Comorbidity Survey Replication. Arch Gen Psychiatry. 2005;62(6):629-640.

13. Petterson S, Miller BF, Payne-Murphy JC, Phillips RL. Mental health treatment in the primary care setting: patterns and pathways. Fam Syst Health. 2014;32(2):157-166.

14. Carcaise-Edinboro $\mathbf{P}$, Bradley $\mathbf{C J}$. Influence of patient-provider communication on colorectal cancer screening. Med Care. 2008;46(7):738-745.

15. Fenton JJ, Jerant AF, Bertakis KD, Franks P. The cost of satisfaction: a national study of patient satisfaction, health care utilization, expenditures, and mortality. Arch Intern Med. 2012;172(5):405-411.

16. Gary TL, Maiese EM, Batts-Turner M, Wang NY, Brancati FL. Patient satisfaction, preventive services, and emergency room use among African-Americans with type 2 diabetes. Dis Manag. 2005;8(6):361-371.

17. Liu Y, Malin JL, Diamant AL, Thind A, Maly RC. Adherence to adjuvant hormone therapy in low-income women with breast cancer: the role of provider-patient communication. Breast Cancer Res Treat. 2013;137(3):829-836.

18. Ratanawongsa N, Karter AJ, Parker MM, et al. Communication and medication refill adherence: the diabetes study of Northern California JAMA Intern Med. 2013;173(3):210-218.

19. Safran DG, Taira DA, Rogers WH, Kosinski M, Ware JE, Tarlov AR. Linking primary care performance to outcomes of care. J Fam Pract. 1998;47(3):213-220.

20. Sequist TD, Schneider EC, Anastario M, et al. Quality monitoring of physicians: linking patients' experiences of care to clinical quality and outcomes. J Gen Intern Med. 2008;23(11):1784-1790.

21. Bauer AM, Parker MM, Schillinger D, et al. Associations between antidepressant adherence and shared decision-making, patient-provider trust, and communication among adults with diabetes: diabetes study of Northern California (DISTANCE). J Gen Intern Med. 2014;29(8):1139-1147.

22. Clever SL, Ford DE, Rubenstein LV, et al. Primary care patients' involvement in decision-making is associated with improvement in depression. Med Care. 2006;44(5):398-405

23. Rossom RC, Solberg LI, Vazquez-Benitez G, et al. The effects of patientcentered depression care on patient satisfaction and depression remission. Fam Pract. 2016;33(6):649-655.

24. Johnston BJ. The role of patient experience and its influence on adherence to antidepressant treatment. J Psychosoc Nurs Ment Health Serv. 2013;51(12):29-37.

25. Kaplan JE, Keeley RD, Engel M, Emsermann C, Brody D. Aspects of patient and clinician language predict adherence to antidepressant medication. J Am Board Fam Med. 2013;26(4):409-420.

26. Loh A, Leonhart R, Wills CE, Simon D, Harter M. The impact of patient participation on adherence and clinical outcome in primary care of depression. Patient Educ Couns. 2007;65(1):69-78.

27. Nelson KM, Helfrich $\mathbf{C}$, Sun $\mathbf{H}$, et al. Implementation of the patientcentered medical home in the veterans health administration: associations with patient satisfaction, quality of care, staff burnout, and hospital and emergency department use. JAMA Intern Med. 2014;174(8):1350-1358.

28. Werner RM, Canamucio A, Shea JA, True G. The medical home transformation in the veterans health administration: an evaluation of early changes in primary care delivery. Health Serv Res. 2014;49(4):1329-47.

29. Szymanski BR, Bohnert KM, Zivin K, McCarthy JF. Integrated care: treatment initiation following positive depression screens. J Gen Intern Med. 2013;28(3):346-352.

30. Yano EM, Chaney EF, Campbell DG, et al. Yield of practice-based depression screening in VA primary care settings. J Gen Intern Med. 2012;27(3):331-338.

31. Zivin $\mathbf{K}$, Pfeiffer PN, Szymanski BR, et al. Initiation of primary care-mental health integration programs in the va health system associations with psychiatric diagnoses in primary care. Med Care. 2010;48(9):843-851.

32. VHA Office of Analytics and Business Intelligence. The shep patient centered medical home (PCMH) survey technical specifications. Washing- ton DC: Department of Veterans Affairs; 2012: http://vaww.car.rtp.med. va.gov/programs/shep/shep.aspx. Accessed 01 May 2018.

33. Frayne SM, Miller DR, Sharkansky EJ, et al. Using administrative data to identify mental illness: what approach is best? Am J Med Qual. 2010;25(1):42-50

34. Hays RD, Berman LJ, Kanter MH, et al. Evaluating the psychometric properties of the CAHPS patient-centered medical home survey. Clin Ther. 2014;36(5):689-696 e681.

35. Scholle SH, Vuong O, Ding L, et al. Development of and field test results for the CAHPS PCMH survey. Med Care. 2012;50(Suppl):S2-10.

36. Jones AL, Mor MK, Cashy JP, et al. Racial/ethnic differences in primary care experiences in patient-centered medical homes among veterans with mental health and substance use disorders. J Gen Intern Med. 2016;31(12):1435-1443

37. Department of Veterans Affairs, Department of Defense. VA/DoD clinical practice guidelilines for the management of major depressive disorder. 2009.

38. Hahm HC, Cook BL, Ault-Brutus A, Alegria M. Intersection of raceethnicity and gender in depression care: screening, access, and minimally adequate treatment. Psychiatr Serv. 2015;66(3):258-264.

39. Watkins KE, Smith B, Akincigil A, et al. The quality of medication treatment for mental disorders in the department of veterans affairs and in private-sector plans. Psychiatr Serv. 2016;67(4):391-396.

40. Burnett-Zeigler I, Zivin K, Ilgen MA, Islam K, Bohnert AS. Perceptions of quality of health care among veterans with psychiatric disorders. Psychiatr Serv. 2011;62(9):1054-1059.

41. Hausmann LR, Gao S, Mor MK, Schaefer JH Jr., Fine MJ. Understanding racial and ethnic differences in patient experiences with outpatient health care in Veterans Affairs Medical Centers. Med Care. 2013;51(6):532-539.

42. Fasoli DR, Glickman ME, Eisen SV. Predisposing characteristics, enabling resources and need as predictors of utilization and clinical outcomes for veterans receiving mental health services. Med Care. 2010;48(4):288-295.

43. Quinones AR, Thielke SM, Beaver KA, Trivedi RB, Williams EC, Fan VS. Racial and ethnic differences in receipt of antidepressants and psychotherapy by veterans with chronic depression. Psychiatr Serv. 2014;65(2): 193-200.

44. Deyo RA, Cherkin DC, Ciol MA. Adapting a clinical comorbidity index for use with ICD-9-CM administrative databases. J Clin Epidemiol. 1992;45(6):613-619.

45. Wray LO, Szymanski BR, Kearney LK, McCarthy JF. Implementation of primary care-mental health integration services in the veterans health administration: program activity and associations with engagement in specialty mental health services. J Clin Psychol Med Settings. 2012;19(1):105-116.

46. Stata [computer program]. Version 13. College Station: StataCorp LP; 2013.

47. Bultman DC, Svarstad BL. Effects of physician communication style on client medication beliefs and adherence with antidepressant treatment. Patient Educ Couns. 2000;40(2):173-185.

48. Butow $\mathbf{P}$, Sharpe $\mathbf{L}$. The impact of communication on adherence in pain management. Pain 2013;154(Suppl 1):S101-107.

49. Sleath B, Rubin RH, Huston SA. Hispanic ethnicity, physician-patient communication, and antidepressant adherence. Compr Psychiatry. 2003;44(3): 198-204

50. Martino SC, Elliott MN, Haviland AM, Saliba D, Burkhart Q, Kanouse DE. Comparing the health care experiences of medicare beneficiaries with and without depressive symptoms in medicare managed care versus feefor-service. Health Serv Res. 2016;51(3):1002-1020.

51. Pfeiffer PN, Szymanski BR, Valenstein M, McCarthy JF, Zivin K. Trends in antidepressant prescribing for new episodes of depression and implications for health system quality measures. Med Care. 2012;50(1):86-90.

52. Kimerling R, Pavao J, Wong A. Patient activation and mental health care experiences among women veterans. Admin Pol Ment Health. 2016;43(4):506-513. 